\title{
Traumatismo Dento-Alveolar: Lesões aos Tecidos de Sustentação (Luxações)
}

Dental-Alveolar Traumatism: Injury to Sustainable Tissue (Luxations)

Traumatismo Dentoalveolar: Lesiones de los Tejidos de Soporte (Dislocaciones)

Erika Thaís Cruz da SILVA

Mestranda em Clínica Odontológica. Faculdade de Odontologia, Universidade de Pernambuco - FOP/UPE, 54.756-220, Camaragibe - PE, Brasil https://orcid.org/0000-0002-8475-7929 Marcelo Gadelha VASCONCELOS

Professor Doutor do Departamento de Odontologia da Universidade Estadual da Paraíba - UEPB, 58429-500, Araruna - PB, Brasil https://orcid.org/0000-0003-0396-553X Rodrigo Gadelha VASCONCELOS

Professor Doutor do Departamento de Odontologia da Universidade Estadual da Paraíba - UEPB, 58429-500, Araruna - PB, Brasil http://orcid.org/0000-0002-7890-8866

\section{Resumo}

Introdução: As lesões aos tecidos de sustentação dentários (luxações) abrangem um grupo de diversas lesões onde o dente é descolado de sua posição original após um acidente traumático. Essas lesões são subclassificadas em: concussão, subluxação, luxação extrusiva, luxação lateral, intrusão e avulsão. Objetivo: Realizar uma revisão de literatura acerca das lesões aos tecidos de sustentação dentários (luxações) abordando aspectos etiológicos, características clínicas e formas de tratamento para cada tipo de lesão. Métodos: Realizou-se uma busca bibliográfica na base de dados PubMed/ Medline, Scielo e Google acadêmico, tendo como filtro publicações dos últimos 10 anos. A busca foi realizada com descritores previamente selecionados. A pesquisa ocorreu em 3 fases e os artigos foram incluídos obedecendo aos critérios de inclusão e exclusão. Resultados: As luxações representam um subgrupo da classificação dos traumatismos dento-alveolar que afetam os tecidos de sustentação dos dentes. De maneira geral, os seguintes tecidos são afetados após uma lesão por luxação: ligamento periodontal ao redor do dente, cavidade óssea alveolar e sistema vascular e nervoso do dente. Podem variar desde uma simples lesão aos tecidos periodontais (concussão) até o completo esmagamento das fibras do ligamento periodontal e do feixe vasculonervoso (intrusão). Conclusão: Essas lesões normalmente requerem uma atenção especial, principalmente no que refere-se aos tecidos periodontais e pulpares, tendo em vista que diversas complicações pós acidente traumático podem ocorrer. Portanto, é importante que o profissional realize um adequado diagnóstico para que o tratamento seja efetivo.

Descritores: Luxações; Traumatismos Dentários; Diagnóstico; Terapêutica.

\section{Abstract}

Introduction: Lesions to the dental support tissues (dislocations) comprise a group of diverse lesions where the tooth is detached from its original position after a traumatic accident. These injuries are subclassified into: concussion, subluxation, extrusive dislocation, lateral dislocation, intrusion and avulsion. Objective: To carry out a literature review about injuries to dental support tissues (dislocations) addressing etiological aspects, clinical characteristics and forms of treatment for each type of injury. Methods: A bibliographic search was performed in the PubMed / Medline, Scielo and Google academic databases, using publications from the last 10 years as a filter. The search was carried out with previously selected descriptors. The research took place in 3 phases and the articles were included according to the inclusion and exclusion criteria. Results: Dislocations represent a subgroup of the classification of dento-alveolar injuries that affect the tissues that support the teeth. In general, the following tissues are affected after a dislocation injury: periodontal ligament around the tooth, alveolar bone cavity and the tooth's vascular and nervous system. They can range from a simple injury to the periodontal tissues (concussion) to the complete crushing of the fibers of the periodontal ligament and the vasculonervous bundle (intrusion). Conclusion: These injuries usually require special attention, especially with regard to periodontal and pulp tissues, considering that several complications after a traumatic accident may occur. Therefore, it is important that the professional makes an adequate diagnosis for the treatment to be effective.

Descriptors: Dislocations; Tooth Injuries; Diagnosis; Therapeutics.

\section{Resumen}

Introducción: Las lesiones de los tejidos de soporte dentario (luxaciones) abarcan un grupo de diversas lesiones donde el diente se desprende de su posición original luego de un accidente traumático. Estas lesiones se subclasifican en: conmoción cerebral, subluxación, luxación extrusiva, luxación lateral, intrusión y avulsión. Objetivo: Realizar una revisión de la literatura sobre las lesiones de los tejidos de soporte dentario (luxaciones) abordando aspectos etiológicos, características clínicas y formas de tratamiento de cada tipo de lesión. Métodos: Se realizó una búsqueda bibliográfica en las bases de datos académicas PubMed / Medline, Scielo y Google, utilizando como filtro publicaciones de los últimos 10 años. La búsqueda se realizó con descriptores previamente seleccionados. La investigación se desarrolló en 3 fases y los artículos se incluyeron según los criterios de inclusión y exclusión. Resultados: Las luxaciones representan un subgrupo de la clasificación de lesiones dentoalveolares que afectan los tejidos que sostienen los dientes. En general, los siguientes tejidos se ven afectados después de una lesión por dislocación: ligamento periodontal alrededor del diente, cavidad del hueso alveolar y sistema vascular y nervioso del diente. Pueden ir desde una simple lesión de los tejidos periodontales (conmoción cerebral) hasta el aplastamiento completo de las fibras del ligamento periodontal y del haz vasculonervioso (intrusión). Conclusión: estas lesiones suelen requerir una atención especial, especialmente en lo que respecta a los tejidos periodontales y pulpares, considerando que pueden presentarse diversas complicaciones tras un accidente traumático. Por tanto, es importante que el profesional realice un diagnóstico adecuado para que el tratamiento sea eficaz.

Descriptores: Luxaciones; Traumatismos de los Dientes; Diagnóstico; Terapéutica.

INTRODUÇÃO

Lesões aos tecidos dentários de sustentação (luxações) compreende um grupo de várias lesões em que o dente é descolado de sua posição original após um acidente traumático. São subclassificadas em: concussão, subluxação, luxação extrusiva, luxação lateral, luxação intrusiva (intrusão) e avulsão'.

De forma semelhante aos outros grupos de traumatismo dentários as luxações possuem como fatores etiológicos principais as quedas, acidentes, agressões físicas e colisões súbitas com objetos. Além disso, também acometem 
principalmente os homens $(60 \%$ a $70 \%$ dos casos) e dentes anteriores (incisivo superior central em $60 \%$ dos casos) ${ }^{1}$.

Podem acometer tanto a dentição decídua quanto a permanente, porém, são mais frequentemente observadas em dentes decíduos. Isso se deve, principalmente, ao fato de que o osso alveolar em dentes decíduos possui maior resiliência em relação ao osso alveolar de dentes permanentes ${ }^{2}$.

Segundo Belmonte et al. ${ }^{1}$ apesar da incidência, das lesões por luxações, ser baixa em dentes permanentes quando comparada às fraturas, o tratamento dessas lesões pode ser mais complexo exigindo, muitas vezes, até mesmo a imobilização dos dentes acometidos. Além do mais, as consequências são geralmente mais graves e podem exigir um prolongado tempo de acompanhamento.

Os seguintes tecidos são afetados após uma lesão por luxação: ligamento periodontal ao redor do dente, cavidade óssea alveolar e sistema vascular e nervoso do dente. Nos casos de intrusão, geralmente esses tecidos são afetados mais gravemente podendo até mesmo ocasionar a perda do dente ${ }^{\text {. }}$

Dessa forma, o presente estudo tem como objetivo realizar revisão de literatura a cerca dos traumatismos dento-alveolares. Serão abordadas as lesões aos tecidos de sustentação dos dentes (luxações) destacando desde aspectos clínicos e etiológicos ao tratamento.

MATERIAL E MÉTODO

Este estudo caracterizou-se por uma busca bibliográfica na base de dados PubMed / Medline, Scielo e Google acadêmico. A pesquisa foi realizada e teve como filtro a publicação dos últimos 10 anos. Também foram adicionados alguns artigos anteriores aos últimos 10 anos considerados relevantes para este estudo. Os descritores utilizados para busca foram: Traumatic dental injuries, Luxations teeth e Injuries alveolar process.

A pesquisa ocorreu em três fases: 1)busca nas bases de dados com os descritores selecionados; 2)leitura dos resumos e definição dos artigos a serem incluídos; 3)leitura dos artigos na íntegra e construção dos resultados.

Como critérios de inclusão, foram adotados os artigos escritos em inglês e português, aqueles que se enquadravam no enfoque do trabalho e os mais relevantes em termos de delineamento das informações desejadas. Dentre os critérios observados para a escolha dos artigos foram considerados os seguintes aspectos: disponibilidade do texto integral do estudo e clareza no detalhamento metodológico utilizado. Alguns livros considerados relevantes para este estudo, também, foram adicionados.

Foram excluídos da amostra os artigos que não apresentavam relevância clínica sobre o tema abordado ou não relacionado ao assunto, bem como artigos não disponíveis e artigos duplicados.

REVISÃO DA LITERATURA

\section{- Concussão}

A concussão representa uma pequena lesão aos tecidos periodontais que não é frequentemente encontrada em decorrência das poucas evidências clínicas e radiográficas que possibilitem diagnosticar esse tipo de trauma. $O$ dente afetado não apresenta mobilidade anormal ou deslocamento, não há sangramento no sulco gengival e mostra-se sensível ao toque ou à percussão 3,4 .

Não há achados radiográficos e nenhum tratamento é indicado nos casos de concussão. Realiza-se apenas o alívio sintomático, retirando o dente de contato oclusal desgastando o dente oposto. Contudo, não se deve esquecer de instituir o acompanhamento da lesão para monitorar a saúde pulpar e periodontal por um período de pelo menos 1 ano. É raro, mas existe a possibilidade de encontrarmos necrose pulpar como sequela de uma concussão nos dentes com rizogênese completa ${ }^{5-7}$.

\section{- Subluxação}

$\mathrm{Na}$ subluxação acontece ruptura de algumas fibras do ligamento periodontal. Não há deslocamento do dente, porém, este é sensível ao toque ou à percussão e apresenta aumento da mobilidade havendo pequeno sangramento pelo sulco gengival em decorrência da ruptura parcial de fibras do ligamento periodontal e do feixe vasculonervoso. Não são vistas alterações radiográficas rotineiramente $e^{4,8}$.

Normalmente não requer tratamentos sendo necessária apenas a proservação. Contudo, em casos mais graves pode estar indicada a contenção flexível por até 2 semanas, principalmente quando se quer eliminar interferência oclusais que levem à dor $^{5,7}$. É indicado também que o paciente tenha uma alimentação líquido/pastosa durante as primeiras 48 horas ${ }^{7}$. O controle clínico e radiográfico é fundamental por até aproximadamente 1 ano após o trauma, pois complicações pulpares e periapicais podem surgir nesse período ${ }^{5,8}$.

\section{- Luxação extrusiva (extrusão)}

$$
\text { A luxação extrusiva ou extrusão }
$$
caracteriza-se pelo deslocamento parcial do dente para fora do seu alvéolo. O rompimento 
das fibras periodontais é variável e depende do quanto o dente extruiu. Clinicamente, o dente aparenta estar alongado, com excessiva mobilidade e também com a presença de sangramento pelo sulco gengival. Radiograficamente é observado um espaço apical alveolar vazio ${ }^{4,7}$.

O tratamento indicado é a reposição do dente (redução) e contenção o mais rápido possível. Quanto mais cedo o dente for reduzido, maiores serão as possibilidades de revascularização pulpar e adequada regeneração tecidual periodontal ${ }^{7}$. Segundo Fonseca $^{9}$ dentes não tratados por mais de 33 horas exibem maior incidência de necrose pulpar do que os dentes tratados mais precocemente.

A manobra de redução consiste em realizar uma pressão atraumática e constante do dente no sentido apical e a contenção deve ser feita com material flexível por um período de 2 semanas se a lesão for muito recente ${ }^{5,6,9}$.

É muito importante que o paciente faça um acompanhamento endodôntico por 1 ano tendo em vista que $60 \%$ dos dentes com luxação extrusiva e com rizogênese completa sofrem necrose pulpar. Caso a necrose seja detectada, o tratamento endodôntico deve ser instituído o mais rápido possível ${ }^{5,7}$

- Luxação lateral

$\mathrm{Na}$ luxação lateral ocorre um deslocamento do dente em uma direção diferente daquela do eixo axial, geralmente no sentido vestibular ou lingual. Na maioria das vezes, o dente fica imóvel devido à um travamento do dente no alvéolo com consequente fratura na parede alveolar. É possível observar, também, um som agudo semelhante ao de anquilose no momento da percussão $^{4,7}$

Dentes com luxações laterais são vistos radiograficamente com aumento do espaço do ligamento periodontal em direção apical assemelhando-se aos dentes extruídos. Em alguns casos, pode ser visto a perda do suporte ósseo marginal que pode ser temporária ou permanente, sendo vista clinicamente como um crescimento de tecido de granulação no sulco gengival que resulta em perda de inserção. Esse processo dura cerca de 6 à 8 semanas e 0 paciente deve ser conscientizado quanto à correta manutenção da higiene bucal para evitar perdas ósseas futuras ${ }^{3}$.

O tratamento consiste em reposicioná-lo com o dedo no vestíbulo para que o dente desencaixe do bloqueio ósseo e retorne à sua posição normal. Depois, realiza-se a contenção flexível do dente por um período de 4 semanas $^{4,5,8}$ Caso ocorra a necrose pulpar, realiza-se o tratamento do canal radicular a fim de evitar reabsorção radicular ${ }^{4}$.

O paciente deve ser orientado a ter uma alimentação líquido-pastosa nos primeiros dias. Podem ser prescritos também anti-inflamatórios e colutórios de $\mathrm{CHX}$ durante a primeira semana. O acompanhamento é recomendado por um período de até 5 anos para o monitoramento da saúde pulpar?.

- Luxação intrusiva (intrusão)

A luxação intrusiva ou intrusão dentária ou simplesmente intrusão representa a compressão do dente no alvéolo dental e através do osso alveolar. A intrusão pode variar desde a mínima impacção até o completo desaparecimento do dente no alvéolo e nos maxilares de suporte e representa uma forma grave de $\operatorname{TDA}^{9,10}$. Na dentição permanente é um achado incomum, representando apenas cerca de $2 \%$ das lesões, sendo mais comum na dentição decídua onde compreende 8 à $22 \%$ de todas as lesões de luxação dos dentes anteriores decíduos ${ }^{11,12}$.

Geralmente há sangramento gengival e também ocorre um completo esmagamento das fibras do LPD. Além disso, o feixe vasculonervoso é totalmente comprimido em seu alvéolo ${ }^{13}$. Em decorrência disso, existe grande incidência de reabsorção radicular inflamatória da raiz, necrose pulpar, perda do osso marginal, obliteração parcial ou total do canal pulpar, anquilose e recessão gengival ${ }^{9,10,12}$.

Segundo Braga et al. ${ }^{10}, 100 \%$ dos casos de dentes intruídos com rizogênese completa sofrem necrose. Em dentes com rizogênese incompleta o índice de necrose é em $60 \%$ dos $\operatorname{casos}^{14}$.

Ao exame clínico o dente poderá parecer imperceptível ou em casos mais severos, poderá parecer ausente. Para que se consiga distinguir um dente intruído de um dente parcialmente erupcionado ou não-erupcionado realiza-se a percussão; se o dente estiver intruído, ele apresenta um som metálico assemelhando-se à um dente anquilosado. Além do som metálico, o dente intruído apresenta outras características semelhantes ao dente anquilosado, como ausência de mobilidade e sensibilidade na percussão vertical $^{6,7}$.

A intrusão dentária faz com que ocorra uma íntima adaptação da lâmina dura com a superfície radicular. Por esse motivo, podem apresentar mínimos achados radiográficos sendo observado o desaparecimento parcial ou total do espaço do LPD na radiografia; esse tipo 
de deslocamento dentário possui o pior prognóstico ${ }^{6,7,9}$.

De acordo com o grau de deslocamento clínico, os dentes intruídos podem ser classificados em 3 categorias: intrusão leve $(<3$ $\mathrm{mm})$, moderada $(3-6 \mathrm{~mm})$ e severa $(>6 \mathrm{~mm})^{15}$. Gupta $^{11}$ ainda traz outra classificação onde é avaliado se a coroa dentária encontra-se visível ou não, podendo classificar da seguinte maneira: grau I (intrusão parcial leve na qual mais de $50 \%$ da coroa é visível), grau II (intrusão parcial moderada na qual menos de $50 \%$ da coroa é visível) e grau III (intrusão grave ou completa da coroa).

O tratamento do dente intruído é controverso e segundo Fonseca ${ }^{9}$ não existe um tratamento ideal estabelecido. Segundo Rai et al. ${ }^{12}$, a re-erupção espontânea em casos de intrusão dentária ocorre particularmente quando a polpa dentária é vital e raramente ocorre quando a necrose pulpar é estabelecida.

Costa et al. $^{13}$ realizaram uma revisão sistemática para avaliar os efeitos dos três tratamentos relatados na literatura para a intrusão: re-erupção espontânea, reposicionamento ortodôntico e reposicionamento cirúrgico, usados para um ou mais dentes permanentes que sofreu luxação intrusiva. Foi possível observar que, a reerupção espontânea mostrou ter 0 melhor prognóstico para defeitos ósseos e alterações pulpares em comparação com 0 reposicionamento ativo (ortodôntico e cirúrgico).

A explicação para isso pode estar no fato de que as forças de tração ortodônticas podem levar a danos adicionais, ao contrário da reerupção, que consiste em uma forma mais fisiológica do dente retornar à sua posição original. Além disso, foi visto que dentes com formação radicular incompleta exibem melhor prognóstico, pois possuem melhor capacidade regeneradora.

Conforme já citado, o tratamento é controverso e diversos aspectos devem ser considerados. O protocolo de tratamento da IADT ressalta todas as condutas de tratamento para as intrusões, que existe conflito e/ou divergência de opinião sobre a eficácia do procedimento. Alguns recomendam a exposição cirúrgica e esplintagem; outros defendem que se os dentes intruídos não forem manipulados eles irão reerupcionar normalmente $e$ há também aqueles que usam forças ortodônticas para ajudar na reerupção dentária. Isto tudo pode variar também acordo com o grau de intrusão dentária ${ }^{7,13}$.

Rai et al. ${ }^{12}$ utilizam os seguintes termos para essas possibilidades de tratamento nos casos de intrusão dentária: observação de erupção espontânea (reposicionamento passivo), exposição cirúrgica da coroa e extrusão ortodôntica (reposicionamento ativo) ou extrusão cirúrgica (reposicionamento imediato).

Se a erupção ortodôntica assistida for instituída, ela deve ser feita de forma lenta e com baixa força por 3 a 4 semanas. Quando o dente já estiver em sua posição adequada na arcada, realiza-se a esplintagem por 2 a 3 meses $^{6}$.

Dentes decíduos que estão intruídos a ponto de tocar o folículo do dente sucessor devem ser extraídos o mais atraumaticamente possível. Já aqueles dentes que não estão próximos ao sucessor, a reerupção é comum e, por esse motivo, recomenda-se apenas um período de observação ${ }^{6}$.

Nos casos de dentes decíduos em que optar-se por esperar a reerupção espontânea é importante que os pais estejam atentos aos sinais e sintomas que podem surgir; como inchaço dos tecidos gengivais circundantes, vermelhidão, dor, exsudato purulento e sintomas sistêmicos como febre. Se algum destes sinais estiverem presentes os pais devem ser orientados à procurar imediatamente - dentista e este deve intervir com a antibioticoterapia para evitar a disseminação da inflamação ao germe dentário permanente ${ }^{11}$.

O tratamento pode variar ainda de acordo com a formação radicular. Dentes com rizogênese incompleta é recomendável aguardar que a reerupção espontânea ocorra naturalmente. Se isso não ocorrer dentro de um período de até 3 semanas, indica-se 0 reposicionamento ortodôntico rápido. Para os casos de dentes intruídos mais de $7 \mathrm{~mm}$ indicase reposicionar cirúrgicamente ou ortodonticamente $^{4,5,15}$. Nos casos em que 0 dente apresenta a rizogênese completa deve-se adotar as seguintes recomendações descritas na tabela 1.

Tabela 1. Recomendações a serem observadas para o tratamento de dentes com intrusão que apresentam rizogênese completa.

\begin{tabular}{l|lllll}
\hline Intrusão (<3mm) & $\begin{array}{l}\text { Aguardar } \\
\text { espontaneamente. Se não obtiver sucesso, faz-se o } \\
\text { resposicionamento cirúrgico ou ortodôntico. }\end{array}$ \\
\hline Intrusão (3-7mm) & $\begin{array}{l}\text { Reposicionar assim que possível de forma cirúrgica ou } \\
\text { ortodôntica. }\end{array}$ \\
\hline Intrusão (>7mm) & $\begin{array}{l}\text { Intrusão grave em que deve } \\
\text { reposicionamento cirúrgico. }\end{array}$ & ser feito & 0 \\
\hline Fonte: Adaptação & 4,12
\end{tabular}

Após o reposicionamento dentário é importante a estabilização com contenção flexível por 4 a 8 semanas s.5 $^{4}$

Como foi dito anteriormente que a necrose pulpar irá ocorrer na totalidade dos casos, é importante que o tratamento endodôntico seja realizado em até no máximo 3 
semanas após o reposicionamento do dente para prevenir reabsorções radiculares inflamatórias. Além disso, o paciente também deve ser orientado a ter uma alimentação líquido-pastosa e usar colutório de $\mathrm{CHX}$ 2x/dia durante a primeira semana ${ }^{7}$.

- Avulsão

A avulsão consiste no deslocamento completo do dente para fora do seu alvéolo. Esse tipo de traumatismo dentário ocorre com mais frequência em pacientes dos 7 aos 11 anos de idade e representa de $1 \%$ a $16 \%$ de todos os tipos de lesões dentárias que envolvem a dentição permanente. Os dentes mais acometidos são os incisivos centrais superiores. A maioria das avulsões envolve apenas um dente, no entanto, em alguns casos como em acidentes automobilísticos e a prática de esportes, mais de um dente pode ser acometido $^{16,17}$

As orientações devem ser repassadas pelo dentista ao paciente, pais, professores ou responsáveis. Em casos de avulsão dental deve-se limpar o dente com a saliva do paciente, solução salina ou água filtrada e reimplantá-lo imediatamente segurando pela coroa dentária de forma que não toque na raiz. Caso não consiga reimplantar o dente de imediato, deve-se guardá-lo em um meio apropriado e procurar o mais rápido possível o dentista ${ }^{6}$.

Ao chegar ao consultório com a queixa de avulsão dental o paciente deve ser tranquilizado e o CD deverá observar dois aspectos fundamentais para a decisão correta da conduta a ser seguida, são eles: nível de desenvolvimento radicular (ápice fechado ou aberto) e status das células do LPD. Além disso, é imprescindível também obter o histórico completo de como ocorreu o acidente, buscando informações do local onde o dente foi recuperado, tempo que o dente ficou fora do alvéolo e o meio de armazenamento ${ }^{9}$.

É importante não raspar ou manipular a superfície radicular nem o alvéolo dentário antes do reimplante. Isto porque a manipulação pode destruir o tecido periodontal viável. Se houver coágulo no interior do alvéolo este pode ser removido delicadamente irrigando com solução salina ${ }^{4}$.

Segundo as diretrizes da IADT as condições das células do ligamento periodontal podem ser classificadas nas seguintes categorias apresentadas na tabela 2.

Os fatores mais importantes que determinam o sucesso do tratamento são: o tempo em que o dente está fora do alvéolo, o estado do dente, dos tecidos periodontais e a maneira pelo qual o dente foi armazenado antes do reimplante. $O$ prognóstico será melhor quanto mais cedo for realizado o reimplante ${ }^{5}$.

É fundamental certificar-se que se trata de um dente permanente para reimplantá-lo, pois dentes decíduos não devem ser reimplantados por causa do risco de lesão no dente permanente subjacente $e^{5,18}$.

$\mathrm{Na}$ literatura existem inúmeros meios de armazenagem recomendados para dentes avulsionados, conforme demonstrado na tabela 3. No entanto, existem controvérsias em definir qual o mais seguro. Os meios de armazenagem mais conhecidos para dentes avulsionados são: água, solução salina, solução salina balanceada de Hanks (HBSS, do inglês Hank's balanced salt solution), saliva, leite e recipientes contendo meios especiais de cultura e produtos médicos/ hospitalares desenvolvidos especificamente para fins de armazenamento de órgãos, como o Viaspan ${ }^{\circledR} \mathrm{e}$ o Euro-Collins ${ }^{19}$.

Tabela 2. Classificação do status das células do ligamento periodontal em dentes avulsionados

\begin{tabular}{l|l}
\hline Condição do ligamento periodontal & \multicolumn{1}{c}{ Conduta clínica } \\
\hline $\begin{array}{l}\text { 1. Células do LPD muito provavelmente } \\
\text { viáveis }\end{array}$ & $\begin{array}{l}\text { Dente reimplantado imediatamente ou } \\
\text { num tempo muito curto depois do } \\
\text { acidente. }\end{array}$ \\
\hline $\begin{array}{l}\text { 2. Células do LPD que podem ser viáveis, } \\
\text { mas estão comprometidas }\end{array}$ & $\begin{array}{l}\text { Dente mantido em meio de preservação } \\
\text { e o tempo total do acidente é inferior a } \\
\text { 6o minutos. }\end{array}$ \\
\hline 3. Células inviáveis do LPD & $\begin{array}{l}\text { Tempo total de preservação em } \\
\text { ambiente extraoral é superior a 6omin, } \\
\text { independente do meio de preservação. }\end{array}$ \\
\hline Fonte: Adaptado &
\end{tabular}

Tabela 3. Comparação do pH e Osmolaridade dos diferentes meios de estocagem

\begin{tabular}{l|c|c}
\hline \multicolumn{1}{c|}{ Meio de armazenagem } & Ph & Osmolaridade (mOsm/kg) \\
\hline Solução salina & 7,0 & 295 \\
\hline Água potável & 7,5 & 12 \\
\hline Saliva & 6,3 & $110-120$ \\
\hline Viaspan ${ }^{\circledR}$ & 7,4 & 320 \\
\hline Leite & 6,75 & 275 \\
\hline Água de coco & 6,2 & 288 \\
\hline Plasma Sanguíneo & $7,2-7,4$ & 290 \\
\hline Solução salina balanceada de Hanks & 7,0 & $270-290$ \\
\hline Fonte: Fonseca &
\end{tabular}

Desses meios, podemos inferir que a água é o menos recomendado por ser hipotônica e causar lise celular. Já a saliva, possui a vantagem de manter o dente úmido, porém não é ideal devido à osmolaridade e pH incompatíveis. Sendo assim, os autores trazem como o mais apropriado a solução salina balanceada de Hanks. Contudo, na maioria das situações esta solução pode não estar disponível, pelo custo e por não ser de fácil acesso $^{6,9}$. Por esse motivo, indica-se o leite como meio alternativo mais adequado, pois, pode ser facilmente adquirido, possui $\mathrm{pH}$ e osmolaridade compatíveis aos das células vitais e, além disso, é relativamente livre de bactérias mostrando-se eficaz na manutenção da vitalidade das células do $\mathrm{LPD}^{16}$.

De acordo com Poi et al. ${ }^{17}$ a viabilidade das células do ligamento periodontal em contato com o leite foi avaliada por vários autores e foi 
possível observar taxas de sobrevivência de 70 à $90 \%$ com baixa frequência de reabsorções radiculares.

Segundo Tuna et al. ${ }^{20}$ para que um meio de armazenagem sejam considerado ideal na capacidade de manter a viabilidade das células pulpares e do LPD ele deve conter as seguintes características: propriedade antioxidante, mínima contaminação bacteriana, pH fisiológico, osmolaridade compatível com a do dente, baixo custo, fácil acessibilidade e alta disponibilidade.

A doxiciclina (DOX) parece possuir a capacidade de revascularização dos elementos dentários avulsionados, principalmente aqueles com rizogênese incompleta. Para isso, o dente deve ser mantido antes do reimplante por 5 minutos em solução salina de doxiciclina $(100 \mathrm{mg}-20 \mathrm{ml} \text { de soro fisiológico })^{18}$.

A opção pelo reimplante traz controvérsias entre os diversos autores que discutem este tema. A maioria dos autores concorda que o dente deve ser reposicionado no alvéolo dentro da primeira hora decorrida após acidente. Caso isso não seja possível, o prognóstico será muito desfavorável e consequências posteriores como anquilose e reabsorção inflamatória são esperadas. De forma que, alguns profissionais contraindicam o reimplante nessa situação. Karayilmaz et al. ${ }^{21}$ observaram em seu estudo que o período extraalveolar deve ser de no máximo 20 a 30 minutos para o melhor prognóstico possível.

Em lesões por avulsão dentária quanto mais rapidamente o dente for reimplantado no alvéolo, melhor será o prognóstico e a cicatrização dos tecidos periodontais. Estudos clínicos e experimentais demonstraram que dos dentes reimplantados após um máximo de cinco minutos apenas $73 \%$ apresentaram uma cicatrização normal, aumentando o tempo do dente fora do alvéolo para 10 minutos a cicatrização ótima foi observada em apenas $50 \%$ dos $\operatorname{casos}^{22}$. De acordo com Steiner ${ }^{23}$ diversos autores demonstraram taxas de sucesso entre $71 \%$ e $82 \%$ quando dentes avulsionados são reimplantados sob condições mais favoráveis.

Segundo Fonseca $^{9}$ existem algumas condições que precisam estar presentes para que o dente permanente seja reimplantado: 0 dente avulsionado não deve apresentar doença periodontal avançada, o alvéolo dentário deve estar razoavelmente intacto para alojar o dente, ausência de alterações ortodônticas significativas (tais como apinhamentos), avaliar e considerar 0 tempo de permanência extraalveolar.

Um melhor prognóstico será obtido nas seguintes condições: manejo e manutenção adequada do dente até 0 momento do reimplante, terapia endodôntica, administração de antibióticos sistêmicos e tempo extra-alveolar o mais curto possível ${ }^{17}$. Além disso, de acordo com Miloro et al. $^{3}$ dentes com ápice radicular aberto apresentam melhor prognóstico do que aqueles com ápice radicular fechado.

Apesar das condições expostas anteriormente, o profissional pode optar pelo reimplante tardio do dente com rizogênese completa. Nessa situação, é muito importante remover todo o LPD que se encontra necrótico. Depois o dente deve ser lavado com solução salina ou água destilada. Posteriormente, quando o dente estiver posicionado no interior do alvéolo, ele deve ser suavemente pressionado em sentido apical por cerca de 3 minutos ${ }^{7}$.

Segundo Chafaie $^{2}$, nesses casos de reimplante tardio, deve-se mergulhar o dente em uma solução de fluoreto de sódio a $2 \%$ por 20 minutos permite evitar a reabsorção inflamatória da raiz.

Após isso, será realizada a estabilização normalmente através da contenção flexível. Se não houver fratura da parede alveolar o tempo de esplintagem é de no máximo 10 dias. Se concomitante à avulsão houver fratura da parede alveolar a esplintagem deve permanecer por um período de 4 a 6 semanas. Os cuidados com os princípios biológicos devem ser estabelecidos, principalmente no que se refere ao ajuste oclusal, tendo em vista que o elemento não deve estar em oclusão traumática, para que 0 processo de regeneração tecidual aconteça da maneira correta ${ }^{7}$.

Diversos materiais podem ser utilizados para promover a estabilização de dentes avulsionados, como exemplos temos os fios de aço, barras, splints, fios de náilon. É importante que 0 dispositivo de estabilização esteja posicionado o mais longe possível das raízes dentárias. A estabilização não deve ser totalmente rígida, pois isto pode predispor à anquilose e a reabsorção externa da raiz, além disso, o dispositivo deve ser de fácil aplicação e removido facilmente com os instrumentos disponíveis no consultório ${ }^{6}$.

Para os casos de dentes com o ápice fechado e que permaneceram um período de tempo prolongado fora do alvéolo, deve-se realizar o tratamento endodôntico logo após o tempo de contenção ${ }^{7}$.

O uso de antibióticos sistêmicos como forma de prevenir reabsorções radiculares deve ser considerado. É indicado iniciar em até 3 
horas após o reimplante, a medicação de escolha é a amoxicilina. A prescrição de antibióticos deve ser feita na dose apropriada para a idade e o peso do paciente, por um período de 7 à 10 dias $^{18,6}$.

Além disso, podem ser prescritos antiinflamatórios e colutórios de clorexidina. O paciente deve ser orientado a ter uma alimentação líquido/pastosa durante a primeira semana ${ }^{7}$. Segundo Andersson et al. ${ }^{18}$, os dentes reimplantados devem ser monitorados clinicamente e radiograficamente após 4 semanas, 3 meses, 6 meses, 1 ano e, em seguida, anualmente. $O$ exame clínico e radiográfico irá fornecer informações para determinar o prognóstico do dente.

Entre as complicações decorrentes do reimplante de dentes avulsionados podemos trazer como principal a reabsorção radicular que ocorre em cerca de 50 a $76 \%$ dos casos, que pode acontecer devido à necrose pulpar ou do ligamento periodontal comprometido ${ }^{18}$. Além disso, a anquilose é também bastante frequente nos casos de reimplante tardio ${ }^{24}$.

CONCLUSÃO

As luxações dentárias representam um amplo grupo de lesões que afetam os tecidos de sustentação dos dentes. Essas lesões normalmente requerem uma atenção especial, principalmente no que se refere aos tecidos periodontais e pulpares, tendo em vista que diversas complicações pós-acidentes traumáticos podem ocorrer. Portanto, é importante que 0 profissional realize um adequado diagnóstico para que o tratamento seja efetivo. Além disso, na maioria dos casos, é necessário que seja feito o acompanhamento clínico e radiográfico do paciente por, no mínimo, um ano após ocorrência da lesão.

\section{REFERÊNCIAS}

1. Belmonte FM, Day P, Macedo CR, Saconato H, Trevisani VFM. Interventions for treating traumatised permanent front teeth: luxated (dislodged) teeth. Cochrane Database Syst Rev. 2013;(4):CD006203.

2. Chafaie A. Partial and total luxations of permanent teeth in children: Clinical management. Int Orthod. 2016;14(1):32-47.

3. Miloro M, Ghali GE, Larsen PE, Waite PD. Princípios de cirurgia bucomaxilofacial de Peterson. 3.ed. São Paulo: Santos; 2016.

4. Pogrel MA, Kahnberg KE, Anderson L. Cirurgia bucomaxilofacial. Rio de Janeiro: Santos; 2016.

5. Diangelis AJ, Andreasen JO, Ebeleseder KA, Kenny DJ, Trope M, Sigurdsson A. et al. International Association of Dental Traumatology guidelines for the management of traumatic dental injuries: 1. Fractures and luxations of permanent teeth. Dent Traumatol. 2012;28(3):2-12.

6. Hupp JR., Ellis III, Tucker MR. Cirurgia oral e maxilofacial contemporânea. 6. ed. Elsevier: Rio de Janeiro; 2015.

7. Prado R, Salim M. Cirurgia bucomaxilofacial: diagnóstico e tratamento. 2. ed. Rio de Janeiro: Guanabara Koogan; 2018.

8. Guedes Pinto AC. Odontopediatria. 9.ed. São Paulo: Santos; 2016.

9. Fonseca RJ, Walker RV, Barber HD, Powers MP, Frost DE. Trauma Bucomaxilofacial. 4. ed. Rio de Janeiro: Elsevier; 2015.

10. Braga RA, Braga WDF, Girelli CFM, Lacerda MFL, Coelho RG, Junqueira RB. Intrusive Dislocation in Permanent Teeth: Review of Literature and Clinical Case Report. Int J Odontostomat. 2019;13(1):89-92.

11. Gupta M. Intrusive luxation in primary teeth Review of literature and report of a case. Saudi Dent J. 2011;23(4):167-76.

12. Rai P, Pandey RK, Khanna RA. Multidisciplinary approach to the management of traumatic intrusion in immature permanent teeth. BMJ Case Rep. 2016;19.

13. Costa LA, Rlbeiro CCC, Cantanhede LM, Santiago Junior JF, Mendonça MR, Pereira ALP. Treatments for intrusive luxation in permanent teeth: a systematic review and meta-analysis. Int J Oral Maxillofac Surg. 2017; 46(2):214-29.

14. Sarkar PA, Shigli A. Management of traumatic intrusive luxation of incisors in a patient with Down's syndrome. BMJ Case Rep. 2011; 1020114887.

15. Srivastava A, Gupta N, Marleau A, Afrashtehfar $\mathrm{KI}$. How do I manage a patiente with intrusion of a permanente incisor? J Can Dent Assoc. 2014; 80:e50.

16. Adnan S, Lone MM, Khan FR, Hussain SM, Nagi SE. Which is the most recommended medium for the storage and transport of avulsed teeth? A systematic review. Dent Traumatol. 2018;34(2):59-70.

17.Poi WR, Sonoda CK, Martins CM, Melo ME, Pellizzer EP, Mendonça MR. et al. Storage Media For Avulsed Teeth: A Literature Review. Braz Dent J. 2013;24(5):473-85.

18. Andersson L, Andreasen JO, Day P, Heithersay G, Trope M, Diangelis AJ et al. International Association of Dental Traumatology guidelines for the management of traumatic dental injuries: 2. Avulsion of permanente teeth. Dent Traumatol. 2012;28(3):88-96.

19. Munavalli NA, Sachhi RJ, Kambale SS, Bandekar SD. Maintaining vitality of immediately reimplanted avulsed tooth: Twoyear follow-up case report. J. Indian Soc. Pedod. Prev. Dent. 2013;31(2):113-17.

20. Tuna EB, Yaman D, Yamamato S. What is the Best Root Surface Treatment for Avulsed Teeth? Open Dent J. 2014;8:175-79. 
21. Karayilmaz $H$, Kirzioglu Z, Gungor OE. Aetiology, treatment patterns and long-term outcomes of tooth avulsion in children and adolescents. Pak J Med Sci, Saddar. 2013; 29(2):464-68.

22. Brullmann D, Schulze RK, D'hoedt B. The treatment of anterior dental trauma. Dtsch Arztebl Int. 2011;108(34-35):565-70.

23. Steiner DR. Avulsed maxillary central incisors: The case for replantation. Am J Orthod Dentofacial Orthop. 2012;142(1):8-16.

24. Soares AJ, Prado M, Lima TFR, Gomes BPFA, Zaia AA, Souza-Filho FJ. The Multidisciplinary Management of Avulsed Teeth: A Case Report. Iran Endod J. 2012;7(4):203-6.

\section{CONFLITO DE INTERESSES}

Os autores declaram não haver conflitos de interesse

\section{AUTOR PARA CORRESPONDÊNCIA}

\section{Rodrigo Gadelha Vasconcelos}

Universidade Estadual da Paraíba

Av. Coronel Pedro Targino,

58233-000 Araruna-PB, Brasil

Tel: (83) 3373-1040

e-mail: rodrigogadelhavasconcelos@yahoo.com.br 